\title{
CARBON EMISSION ESTIMATION DUE TO LAND COVER CHANGE IN THE TROPICAL FOREST LANDSCAPE IN JAMBI PROVINCE
}

\section{ESTIMASI EMISI KARBON AKIBAT PERUBAHAN PENUTUP LAHAN PADA LANSKAP HUTAN TROPIS DI PROVINSI JAMBI}

\author{
Dian Nuraini Melati ${ }^{1}$ \\ ${ }^{1}$ Pusat Teknologi Reduksi Risiko Bencana (PTRRB), Kedeputian TPSA - Badan Pengkajian dan \\ Penerapan Teknologi (BPPT) \\ Gedung Geostech, Lantai 1, Kompleks Puspiptek Serpong, Tangerang Selatan \\ e-mail: dian.nuraini@bppt.go.id
}

\begin{abstract}
Land use land cover change and forestry play an important role in the global environmental change. Anthropogenic activities in changing the land have caused earth surface change. This change has a role to increase the change of global greenhouse gases in the atmosphere which also causes the increase greenhouse gases emission. Land cover change and forestry are sectors which cause high carbon emission. Therefore, a study in land cover change and estimation of carbon emission becomes important. This study took place in Jambi Province where deforestation has been in a high pace. In 2009 and 2011, the dominant area is dryland agriculture mixed with bush followed by secondary forest, i.e. $25 \%$ and $18.6 \%$, respectively (in 2009); and $37.1 \%$ and 18.9\%, respectively (in 2011). For the secondary forest, the gain was caused by the conversion of dryland agriculture mixed with bush and shrub into secondary forest. The loss of secondary forest is the highest among other forest cover at around 87,765 Ha due to the conversion into bare land and dryland agriculture mixed with bush. Due to land cover change in Jambi Province, the estimation of nett emission in the period of 2009-2011 is $4.8 \mathrm{Mt} \mathrm{CO}_{2}$-eq/year.
\end{abstract}

Keywords: carbon emission, land cover change, deforestation

\begin{abstract}
ABSTRAK
Perubahan penutupan ataupun penggunaan lahan dan hutan menjadi hal yang sangat berpengaruh bagi perubahan lingkungan secara global. Kegiatan antropogenik dalam merubah tutupan lahan mengakibatkan perubahan permukaan bumi yang cukup besar. Perubahan ini tentu saja berperan serta dalam peningkatan perubahan gas-gas di atmosfer secara global yang menjadi penyebab meningkatnya emisi gas rumah kaca. Perubahan penutup lahan dan hutan menjadi salah satu sektor yang menyumbang emisi karbon dalam jumlah yang tinggi. Oleh karena itu studi perubahan penutup lahan dan estimasi emisi karbon pada sektor ini menjadi sangat penting. Lokasi studi terletak di Provinsi Jambi yang merupakan salah satu daerah dengan laju deforestasi yang tinggi. Pada tahun 2009 dan 2011, penutup lahan terluas adalah pertanian lahan kering bercampur dengan semak, lalu diikuti dengan penutup lahan hutan sekunder, dengan luas masing-masing yaitu $25 \%$ dan 18,6\% di tahun 2009 dari luas keseluruhan Provinsi. Pada tahun 2011, peningkatan tutupan pertanian lahan kering bercampur dengan semak cukup tinggi yaitu menjadi $37.1 \%$, sedangkan penutup lahan hutan sekunder hanya terjadi sedikit peningkatan yaitu menjadi $18.9 \%$. Penambahan (gain) luas hutan sekunder ini dikarenakan adanya perubahan tutupan pertanian lahan kering bercampur dengan semak dan belukar menjadi hutan sekunder. Namun demikian, kehilangan (loss) hutan sekunder memiliki nilai yang lebih tinggi dibandingkan tutupan hutan lainnya sebesar 87.765 Ha sebagai akibat perubahan lahan yang besar menjadi tanah terbuka dan pertanian lahan kering bercampur dengan semak. Sebagai akibat perubahan penutup lahan di Provinsi Jambi ini, nilai estimasi emisi bersih pada periode 2009-2011 yaitu 4,8 $\mathrm{Mt} \mathrm{CO}_{2}$-eq/tahun.
\end{abstract}

Kata kunci: emisi karbon, perubahan penutup lahan, deforestasi 


\section{PENDAHULUAN}

\subsection{Latar Belakang}

Perubahan penutupan maupun penggunaan lahan merupakan faktor terpenting yang menyebabkan perubahan lingkungan secara global (Wyman \& Stein, 2010). Aktivitas antropogenik dalam merubah tutupan lahan seperti perubahan hutan menjadi lahan pertanian mengakibatkan banyaknya perubahan permukaan bumi. Perubahan penutupan lahan ini dapat meningkatkan perubahan gas-gas di atmosfer secara global sehingga dapat meningkatkan emisi gas rumah kaca (GRK) (IPCC, 2007). Perubahan tutupan hutan banyak terjadi di berbagai daerah tropis, seperti yang terletak di Amazon, Congo Basin, dan Asia Tenggara yaitu sekitar 227 Mha di tahun 2010, dengan estimasi tingkat deforestasi yaitu 3.8 Mha per tahun antara tahun 1950 dan 2010 (Rosa et al., 2016).

Hutan tropis dapat berperan sebagai sumber karbon dioksida $\left(\mathrm{CO}_{2}\right)$ melalui aktivitas kebakaran hutan, dekomposisi, dan juga deforestasi (Malhi \& Marthews, 2013). Selain itu, hutan juga memiliki peran sebagai penyerap karbon. Penyerapan terjadi melalui proses fotosintesis (Marcus, 2009). Oleh karena itu, hutan tropis memiliki peranan yang penting dalam siklus karbon secara global. Hutan hujan tropis mampu menyimpan cadangan karbon secara ekstensif pada biomassa tegakan, nekromassa, seresah, dan tanah. Pada umumnya, hutan hujan tropis mampu menyimpan biomassa di atas tanah sebesar 200-600 ton/ha (Ghazoul \& Sheil, 2010).

Di Indonesia, total emisi GRK pada tahun 2000 untuk tiga jenis GRK $\left(\mathrm{CO}_{2}, \mathrm{CH}_{4}, \mathrm{~N}_{2} \mathrm{O}\right.$, PFC) tanpa perubahan penggunaan lahan dan hutan serta kebakaran hutan mencapai 556.728, $78 \mathrm{Gg} \mathrm{CO}_{2}$.eq. Sedangkan dengan penambahan sektor perubahan penggunaan lahan dan hutan serta kebakaran hutan akan mencapai 1.377.982,95 $\mathrm{Gg} \mathrm{CO}_{2}$ eq. Total nilai emisi GRK $\left(\mathrm{CO}_{2}\right.$-eq) yaitu $1.112 .878,82 \mathrm{Gg}$ untuk $\mathrm{CO}_{2}$ yang yang merupakan $80.8 \%$ emisi GRK secara nasional, untuk $\mathrm{CH} 4$ adalah $236617,97 \mathrm{Gg} \mathrm{CO}$-eq atau $17.2 \%$, dan untk $\mathrm{N}_{2} \mathrm{O}$ adalah $28.341,02 \mathrm{CO}_{2}$-eq atau $2 \%(\mathrm{KLH}$, 2010). Sektor utama yang menyumbang emisi tertinggi yaitu perubahan penutup ataupun penggunaan lahan dan kehutanan kemudian diikuti oleh sektor energi, emisi yang terkait dengan kebakaran hutan, sampah, pertanian, dan industri. Dengan demikian studi perubahan penutup lahan dan estimasi emisi karbon pada sektor ini menjadi sangat penting untuk dikaji.

\subsection{Tujuan Penelitian}

Adapun tujuan dari penelitian ini adalah sebagai berikut:

a. Melakukan analisis perubahan penutup lahan di Provinsi Jambi pada periode tahun 2009-2011.

b. Melakukan analisis perubahan penutup hutan (gain and loss) di Provinsi Jambi pada periode tahun 2009-2011.

c. Melakukan analisis emisi karbon sebagai akibat perubahan penutup lahan di Provinsi Jambi pada periode tahun 20092011.

\section{BAHAN DAN METODE}

\subsection{Bahan}

Penelitian ini menggunakan peta penutup lahan yang dikeluarkan oleh Direktorat Inventarisasi dan Pemantauan Sumber Daya Hutan, Direktorat Jenderal Planologi Kehutanan dan Tata Lingkungan, Kementerian Lingkungan Hidup dan Kehutanan. Peta penutup lahan ini merupakan hasil interpretasi dari citra penginderaan jauh dengan teknik manual yaitu digitasi on-screen. Dalam hal ini, Landsat digunakan sebagai sumber utama citra penginderaan jauh. Peta penutup lahan dipilih pada tahun 2009 dan 2011 karena ketersediaan data yang berupa shapefile untuk tahun tersebut yang dapat diakses pada situs webgis KLHK (KLHK, 2019). Klasifikasi penutup lahan didasarkan pada SNI 76452010 (BSN, 2010) dengan jumlah 23 kelas (termasuk awan), 7 kelas merupakan penutupan hutan, dan 15 kelas merupakan penutupan non hutan.

\subsection{Metode}

\subsubsection{Lokasi Penelitian}

Lokasi penelitian terletak di Provinsi Jambi, Sumatra dengan luas 4,9 Mha. Pada periode 2011-2012, Provinsi Jambi mengalami deforestasi tertinggi dengan laju deforestasi yaitu $65.734,2$ ha/tahun, dibandingkan dengan provinsi lain di Pulau Sumatra yang memiliki laju deforestasi antara 1.085 sampai dengan 46.395,9 ha/tahun (KLHK, 2014). Berdasarkan data dari Badan Pusat Statistik (BPS, 2014), rata-rata suhu udara, kelembaban, dan curah hujan di tahun 2013 adalah 26.8 C, $86 \%$, dan $2.609,3 \mathrm{~mm}$. Secara administratif, Provinsi Jambi memiliki dua kota yaitu Kota Jambi dan 
Kota Sungai Penuh serta sembilan Kabupaten. Populasi di Provinsi Jambi pada tahun 2013 yaitu sekitar 3,3 juta. Sebagian besar penduduk di pedesaan adalah 1) transmigran, 2) pemilik lahan baik besar maupun kecil yang mengelola lahan pada tipe berbeda yaitu kayu, dan tanaman perkebunan serta tipe-tipe pertanian lainnya seperti tanaman pertanian dan tanaman buah (Stolle et al., 2003).

\subsubsection{Pengumpulan dan Pengolahan Data}

Peta penutup lahan tahun 2009 (Gambar 1) dan 2011 (Gambar 2) diunduh dari webgis KLHK. Pada peta penutup lahan tahun 2009 tersebut terdapat beberapa poligon kosong. Pada kasus ini, atribut poligon kosong tersebut disesuaikan dengan penutup lahan tahun 2011 dengan asumi bahwa tidak terjadi perubahan lahan yang signifikan dalam kurun waktu dua tahun ini. Selanjutnya dilakukan eliminasi untuk poligon yang memiliki luas kurang dari $1 \mathrm{Ha}$ pada masing-masing peta tersebut. Dengan demikian nilai minimum mapping unit (MMU) peta penutup lahan dalam penelitian ini yaitu $1 \mathrm{Ha}$. Sebagai hasil interpretasi citra optik Landsat yang tidak bebas awan, masing-masing peta memiliki kelas tutupan awan. Peta penutup lahan tahun 2009 memiliki persentase tutupan awan sebesar $0,5 \%$, sedangkan peta penutup lahan

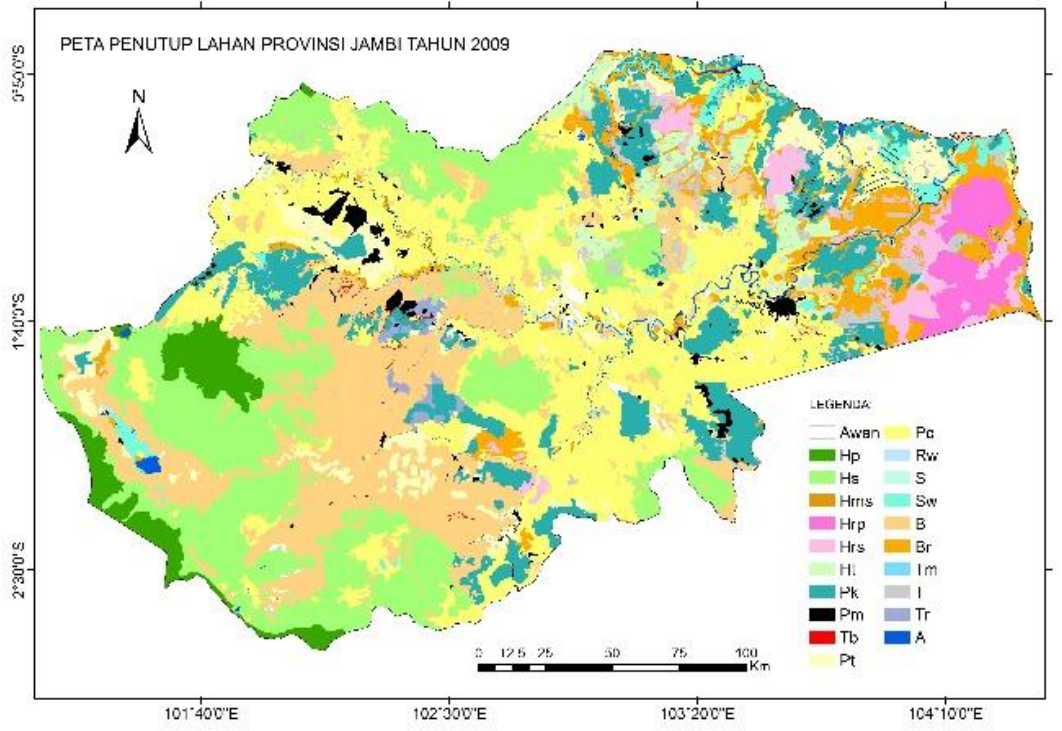

Gambar 1. Peta Penutup Lahan Provinsi Jambi Tahun 2009 (Sumber: KLHK, 2019)

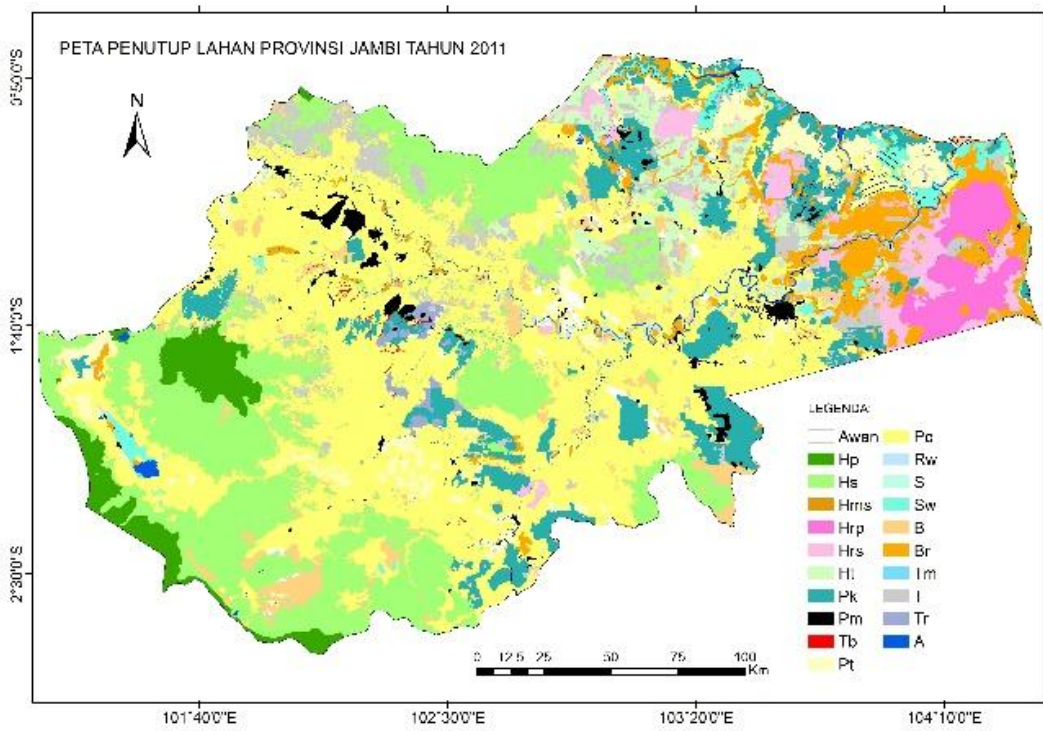

Gambar 2. Peta Penutup Lahan Provinsi Jambi Tahun 2011 (Sumber: KLHK, 2019) 
tahun 2011 memiliki persentase tutupan awan sebesar $0,6 \%$. Berdasarkan peta penutup lahan tersebut, ada 20 kelas yang dapat ditemukan di Provinsi Jambi yaitu hutan lahan kering primer $(\mathrm{Hp})$, hutan lahan kering sekunder (Hs), hutan mangrove sekunder (Hms), hutan rawa primer (Hrp), hutan rawa sekunder $(\mathrm{Hrs})$, hutan tanaman industri $(\mathrm{Ht})$, perkebunan $(\mathrm{Pk})$, permukiman $(\mathrm{Pm})$, pertambangan $(\mathrm{Tb})$, pertanian lahan kering $(\mathrm{Pt})$, pertanian lahan kering bercampur dengan semak $(\mathrm{Pc})$, rawa $(\mathrm{Rw})$, savanna $(\mathrm{S})$, sawah $(\mathrm{Sw})$, semak/belukar (B), semak/belukar rawa $(\mathrm{Br})$, tambak $(\mathrm{Tm})$, tanah terbuka $(\mathrm{T})$, transmigrasi $(\operatorname{Tr})$, dan tubuh air $(\mathrm{A})$.

\subsubsection{Analisis Perubahan Penutup Lahan}

Analisis perubahan penutup lahan dilakukan untuk mengevaluasi perubahan tutupan lahan sehingga dapat diketahui informasi mengenai dinamika transisi antar kelas penutup lahan. Dalam evaluasi perubahan tutupan lahan ini akan dilakukan perhitungan kehilangan (loss) maupun penambahan (gain) luasan. Selanjutnya untuk mengevaluasi transisi perubahan penutup lahan, maka akan dilakukan tumpang susun antara peta penutup lahan tahun 2009 dan 2011. Dari hasil tumpang susun ini maka akan dihasilkan matriks transformasi perubahan penutup lahan. Pada analisis perubahan penutup lahan, kelas tutupan awan tidak digunakan. Selain itu juga akan dilakukan analisis gain and loss per tahun untuk penutup lahan hutan primer dan hutan sekunder pada periode penelitian. Analisis tersebut tidak diperhitungkan untuk penutup lahan hutan tanaman industri karena hutan jenis ini memiliki pengelolalaan tersendiri terkait pemanfaatan kayu yang ada.

\subsubsection{Penghitungan Emisi Karbon}

Penghitungan emisi dilakukan dengan menggunakan data aktivitas yang meliputi penutup lahan dan perubahannya. Data aktivitas merupakan data yang menunjukkan aktivitas yang dapat menyerap maupun melepaskan gas rumah kaca pada kurun waktu tertentu. Data ini dapat berupa data penutup lahan yang dapat diperoleh dari data penginderaan jauh. Perubahan penutup lahan mengakibatkan perubahan atau perbedaan cadangan karbon sebagai akibat perubahan suatu penutup lahan menjadi penutup lahan lain. Dimana emisi karbon terjadi apabila terjadi perubahan penutup lahan dengan cadangan karbon tinggi menjadi penutup lahan dengan cadangan karbon rendah. Pada penelitian ini cadangan karbon yang digunakan sebagai acuan adalah karbon di atas permukaan tanah (above ground carbon).

Untuk setiap kelas penutup lahan, nilai cadangan karbon yang digunakan menggunakan referensi yang bersumber pada Tosiani (2015). Nilai cadangan karbon yang digunakan untuk kelas penutup lahan non hutan digunakan referensi cadangan karbon per hektar pada skala nasional, sedangkan untuk kelas hutan digunakan cadangan karbon per hektar pada skala regional di Pulau Sumatra.

Penghitungan emisi karbon dilakukan dengan menggunakan metode StockDifference (KLH, 2012). Penghitungan ini merupakan hasil dari penghitungan perubahan cadangan karbon untuk setiap kelas penutup lahan yaitu dari nilai karbon tinggi ke nilai karbon rendah yang dihitung pada awal waktu perhitungan dan akhir waktu perhitungan dengan menggunakan rumus 1 )

$\left.\Delta \mathrm{C}=\left(\mathrm{Ct}_{2}-\mathrm{Ct}_{1}\right) /\left(\mathrm{t}_{2}-\mathrm{t}_{1}\right) \ldots \ldots \ldots \ldots \ldots \ldots \ldots 1\right)$

dimana:

$\Delta \mathrm{C}=$ perubahan cadangan karbon per tahun pada setiap tampungan karbon (ton C/tahun) $\mathrm{Ct}_{1}=$ cadangan karbon pada tampungan karbon pada tahun $\mathrm{t}_{1}$ (ton $\mathrm{C}$ )

$\mathrm{Ct}_{2}=$ cadangan karbon pada tampungan karbon pada tahun $\mathrm{t}_{2}$ (ton $\mathrm{C}$ )

Apabila perubahan lahan terjadi dari tutupan lahan yang memiliki nilai karbon rendah menjadi tutupan lahan yang memiliki nilai karbon tinggi misalnya dari semak/belukar menjadi hutan lahan kering sekunder maka terjadi penyerapan karbon. Pada tutupan lahan yang tidak mengalami perubahan, maka diasumsikan pada tutupan lahan ini tidak terjadi emisi maupun serapan. Dengan demikian, studi ini mengkaji nilai emisi maupun serapan karbon sebagai akibat perubahan penutup lahan.

Selanjutnya total emisi/serapan karbon dihitung dengan menggunakan rumus 2). Dalam pendugaan emisi/serapan karbon, nilai cadangan karbon selanjutnya dikalikan dengan 3,67, dengan tujuan untuk mendapatkan nilai kesetaraan terhadap Carbon Dioxide Equivalent ( $\mathrm{CO}_{2}$-eq).

Emisi/Serapan Karbon (total) $=$ Data aktivitas x Faktor Emisi/Faktor Serapan .)

dimana:

data aktivitas merupakan luas perubahan penutup lahan 
faktor emisi/serapan merupakan selisih kandungan karbon akibat emisi/serapan per ha

\section{HASIL DAN PEMBAHASAN}

\subsection{Analisis Perubahan Penutup Lahan}

Berdasarkan peta penutup lahan tahun 2009 dan 2011, luas masing-masing penutup lahan dapat dihitung seperti yang disajikan pada Tabel 1. Dari tabel tersebut dapat dilihat bahwa tutupan pertanian lahan kering bercampur dengan semak memiliki area terluas sebesar $25 \%$ dibandingkan penutup lahan lainnya. Selanjutnya, hutan sekunder menempati area terluas kedua yaitu sekitar $18,6 \%$. Pada tahun 2011, luas area pertanian lahan kering bercampur dengan semak meningkat cukup banyak menjadi $37,1 \%$, sedangkat luas area hutan sekunder hanya meningkat sedikit yaitu menjadi $18,9 \%$. Hal ini mengindikasikan bahwa tanaman yang memiliki nilai ekonomi tinggi telah menyebabkan peningkatan luas area pertanian.

Tabel 1. Luas Penutup Lahan pada tahun 2009 dan 2011 di Provinsi Jambi

\begin{tabular}{|l|c|c|c|c|}
\hline \multirow{2}{*}{$\begin{array}{c}\text { Penutup } \\
\text { Lahan }\end{array}$} & \multicolumn{2}{|c|}{2009} & \multicolumn{2}{c|}{2011} \\
\cline { 2 - 5 } & Luas (Ha) & $\%$ & Luas (Ha) & $\%$ \\
\hline $\mathrm{Hp}$ & 152299.4 & 3.1 & 151867.3 & 3.1 \\
\hline $\mathrm{Hs}$ & 913618.7 & 18.6 & 930526.2 & 18.9 \\
\hline $\mathrm{Hms}$ & 4878.4 & 0.1 & 5032.6 & 0.1 \\
\hline $\mathrm{Hrp}$ & 109543.2 & 2.2 & 120380.6 & 2.4 \\
\hline $\mathrm{Hrs}$ & 124278.9 & 2.5 & 135992.5 & 2.8 \\
\hline $\mathrm{Ht}$ & 91679.1 & 1.9 & 121818.7 & 2.5 \\
\hline $\mathrm{Pk}$ & 456942.8 & 9.3 & 395128.7 & 8.0 \\
\hline $\mathrm{Pm}$ & 73468.2 & 1.5 & 72511.0 & 1.5 \\
\hline $\mathrm{Tb}$ & 4230.5 & 0.1 & 4430.1 & 0.1 \\
\hline $\mathrm{Pt}$ & 249295.5 & 5.1 & 214851.6 & 4.4 \\
\hline $\mathrm{Pc}$ & 1231706.5 & 25.0 & 1824044.6 & 37.1 \\
\hline $\mathrm{Rw}$ & 28012.7 & 0.6 & 28014.5 & 0.6 \\
\hline $\mathrm{S}$ & 494.7 & 0.0 & 279.7 & 0.0 \\
\hline $\mathrm{Sw}$ & 69818.9 & 1.4 & 69392.3 & 1.4 \\
\hline $\mathrm{B}$ & 870529.4 & 17.7 & 179028.9 & 3.6 \\
\hline $\mathrm{Br}$ & 304112.4 & 6.2 & 247292.0 & 5.0 \\
\hline $\mathrm{Tm}$ & 2047.2 & 0.0 & 2047.2 & 0.0 \\
\hline $\mathrm{T}$ & 135016.1 & 2.7 & 256792.6 & 5.2 \\
\hline $\mathrm{Tr}$ & 27310.8 & 0.6 & 26089.9 & 0.5 \\
\hline $\mathrm{A}$ & 43030.3 & 0.9 & 102208.7 & 2.1 \\
\hline
\end{tabular}

Dari matriks perubahan penutup lahan pada periode 2009-2011 (Tabel 3) dapat diperoleh informasi luas area perubahan suatu lahan pada periode 2009-2011. Di antara penutup lahan hutan, hutan sekunder memiliki nilai kehilangan (loss) yang tinggi yaitu sekitar $87.765 \mathrm{Ha}$ (Tabel 2). Sebagian besar hutan sekunder di tahun 2009 berubah menjadi tanah terbuka dan pertanian lahan kering bercampur dengan semak pada tahun 2011.

Namun demikian, hutan sekunder juga mengalami penambahan (gain) yang banyak dibandingkan tutupan hutan lainnya. Peningkatan tersebut sebagai hasil dari meningkatnya luas perubahan pertanian lahan kering bercampur dengan semak dan belukar menjadi hutan sekunder di tahun 2011. Nilai kehilangan yang tertinggi adalah pada penutup lahan belukar yaitu sekitar $721.068 \mathrm{Ha}$ dimana sebagian besar area ini berubah menjadi pertanian lahan kering bercampur dengan semak pada tahun 2011. Hal ini tentu saja diikuti dengan nilai penambahan yang tertinggi pula untuk kelas lahan pertanian lahan kering bercampur dengan semak yaitu mencapai $780.098 \mathrm{Ha}$. Fenomena ini mengindikasikan bahwa tanaman yang memiliki ekonomi tinggi telah menjadi salah satu faktor penting perubahan penutup lahan.

Tabel 2. Luas Kehilangan dan Penambahan Penutup Lahan Periode 2009-2011

\begin{tabular}{c|c|c}
\hline $\begin{array}{c}\text { Penutup } \\
\text { Lahan }\end{array}$ & $\begin{array}{c}\text { Kehilangan } \\
\text { (loss) }\end{array}$ & $\begin{array}{c}\text { Penambahan } \\
\text { (gain) }\end{array}$ \\
\hline $\mathrm{Hp}$ & 1664.37 & 1232.33 \\
\hline $\mathrm{Hs}$ & 87764.6 & 104696 \\
\hline $\mathrm{Hms}$ & 0.22539 & 154.428 \\
\hline $\mathrm{Hrp}$ & 0.14793 & 10837.5 \\
\hline $\mathrm{Hrs}$ & 22703.6 & 34513.2 \\
\hline $\mathrm{Ht}$ & 30393.5 & 60745.2 \\
\hline $\mathrm{Pk}$ & 96918.4 & 35104.3 \\
\hline $\mathrm{Pm}$ & 1346.46 & 389.289 \\
\hline $\mathrm{Tb}$ & 288.468 & 488.153 \\
\hline $\mathrm{Pt}$ & 58989.2 & 24681.8 \\
\hline $\mathrm{Pc}$ & 185741 & 780098 \\
\hline $\mathrm{Rw}$ & 0.01504 & 1.77949 \\
\hline $\mathrm{S}$ & 215.092 & 0.02734 \\
\hline $\mathrm{Sw}$ & 427.917 & 1.27548 \\
\hline $\mathrm{B}$ & 721068 & 30834.9 \\
\hline $\mathrm{Br}$ & 83129.4 & 27133.5 \\
\hline $\mathrm{Tm}$ & 0.10752 & 0.09972 \\
\hline $\mathrm{T}$ & 33931.2 & 155736 \\
\hline $\mathrm{Tr}$ & 1387.36 & 166.474 \\
\hline $\mathrm{A}$ & 0.06062 & 59154.2 \\
\hline & &
\end{tabular}

Untuk penutup lahan non hutan, kehilangan luasan (loss) yang besar juga terjadi pada pertanian lahan kering bercampur dengan semak sebesar $185.741 \mathrm{Ha}$. Hal ini dikarenakan perubahan lahan tersebut menjadi hutan lahan kering sekunder dan tanah terbuka di tahun 2011. 
Tabel 3. Matriks Perubahan Penutup Lahan Periode 2009-2011 di Provinsi Jambi

\begin{tabular}{|c|c|c|c|c|c|c|c|c|c|c|c|c|c|c|c|c|c|c|c|c|c|}
\hline \multirow{2}{*}{ PL 2009} & \multicolumn{20}{|c|}{ Penutup Lahan 2011} & \multirow[b]{2}{*}{ Luas 2009} \\
\hline & $\mathrm{Hp}$ & $\mathrm{Hs}$ & $\mathrm{Hms}$ & Hrp & Hrs & $\mathrm{Ht}$ & $\mathrm{Pk}$ & $\mathrm{Pm}$ & $\mathrm{Tb}$ & $\mathrm{Pt}$ & $\mathrm{Pc}$ & $\mathrm{Rw}$ & $\mathrm{s}$ & $\mathrm{Sw}$ & B & $\mathrm{Br}$ & $\mathrm{Tm}$ & $\mathrm{T}$ & $\operatorname{Tr}$ & A & \\
\hline $\mathrm{Hp}$ & 150,635 & 296 & & & & & & & & 89 & 61 & & & & 514 & & & 640 & & 64 & 152,299 \\
\hline $\mathrm{Hs}$ & 1,232 & 825,813 & & & 442 & 966 & 45 & 0 & 185 & 316 & 24,409 & & & 0 & 10,231 & & & 49,635 & 44 & 260 & 913,577 \\
\hline $\mathrm{Hms}$ & & & 4,878 & & & & 0 & 0 & & 0 & 0 & & & 0 & 0 & 0 & 0 & 0 & & 0 & 4,878 \\
\hline Hrp & & & & 109,543 & 0 & & & & & & & & & & & 0 & & 0 & & 0 & 109,543 \\
\hline Hrs & & 484 & & 10,718 & 101,479 & 639 & 1,757 & 0 & & 441 & 200 & 0 & 0 & 0 & 0 & 6,543 & & 1,921 & & 0 & 124,183 \\
\hline $\mathrm{Ht}$ & & 143 & & & \begin{tabular}{|r|}
5,777 \\
\end{tabular} & 61,074 & 74 & 0 & & 754 & 17 & 0 & & 0 & 197 & 3,514 & & 19,919 & & & 91,467 \\
\hline $\mathrm{Pk}$ & & 1,819 & 8 & 0 & 4,669 & 14,007 & 360,024 & 0 & 91 & 141 & 51,667 & 0 & 0 & 0 & 4,161 & 12,905 & 0 & 7,450 & 0 & 0 & 456,943 \\
\hline $\mathrm{Pm}$ & & 0 & 0 & & 0 & 0 & 39 & 72,122 & 0 & 0 & 1,104 & 0 & 0 & 0 & 0 & 188 & & 15 & 0 & 0 & 73,468 \\
\hline $\mathrm{Tb}$ & & & & & & & 0 & 0 & 3,942 & & 276 & & & & 10 & & & 2 & 0 & 0 & 4,230 \\
\hline $\mathrm{Pt}$ & 0 & 1,045 & 0 & & 37 & 309 & 3,706 & 15 & 17 & 190,170 & 52,570 & 0 & 0 & 0 & 374 & 33 & & 883 & 0 & 0 & 249,159 \\
\hline $\mathrm{Pc}$ & 0 & 58,858 & 0 & & 503 & 3,247 & 13,588 & 354 & 9 & 16,686 & $1,043,474$ & 1 & 0 & 0 & 9,337 & 311 & 0 & 53,448 & 7 & 29,392 & $1,229,214$ \\
\hline $\mathrm{Rw}$ & & & & 0 & & 0 & & & & 0 & 0 & 28,013 & & & 0 & & & 0 & & 0 & 28,013 \\
\hline $\mathrm{S}$ & & 0 & & & 168 & & 0 & 0 & & 2 & 38 & & 280 & & & & & 7 & & 0 & 495 \\
\hline Sw & & 0 & 37 & & 0 & 0 & 0 & 0 & & 218 & 124 & 0 & & 69,391 & 0 & 0 & 0 & 0 & & 48 & 69,819 \\
\hline B & 0 & 39,199 & 0 & & 0 & 27,465 & 3,715 & 19 & 98 & 442 & 632,866 & 0 & & 0 & \begin{tabular}{|l|}
148,131 \\
\end{tabular} & 913 & & 16,348 & 1 & 0 & 869,199 \\
\hline $\mathrm{Br}$ & & 1,999 & 110 & 0 & 18,084 & 6,893 & 8,981 & 0 & 0 & 5,483 & 4,350 & 1 & & 0 & 2,659 & 220,158 & 0 & 5,190 & & 29,379 & 303,288 \\
\hline $\mathrm{Tm}$ & & & 0 & & & & 0 & & & 0 & 0 & 0 & & 0 & & 0 & 2,047 & & & 0 & 2,047 \\
\hline $\mathrm{T}$ & 0 & 816 & 0 & 119 & 4,833 & 7,220 & 3,182 & 0 & 89 & 108 & 11,495 & 0 & & 0 & 3,217 & 2,727 & & 101,056 & 115 & 10 & 134,987 \\
\hline $\mathrm{Tr}$ & & 37 & & & & & 17 & 0 & 0 & 0 & 921 & & & & 135 & & & 277 & 25,923 & 0 & 27,311 \\
\hline A & & & & & 0 & 0 & 0 & 0 & & 0 & 0 & & & & & 0 & & 0 & & 43,030 & 43,030 \\
\hline uas & & & & & & & & & & & & & & & & & & & & & \\
\hline 2011 & 151,867 & 930,509 & 5,033 & $\mid 120,381$ & 135,993 & 121,819 & 395,129 & 72,511 & 4,430 & 214,852 & $1,823,572$ & 28,015 & 280 & 69,392 & $|178,966|$ & 247,292 & 2,047 & 256,793 & 26,090 & 102,184 & $4,887,152$ \\
\hline
\end{tabular}

Pada sektor kehutanan, analisis kehilangan (loss) dan penambahan (gain) (Gambar 3) dibedakan untuk tutupan hutan primer dan hutan sekunder. Hutan primer meliputi hutan primer dan hutan rawa primer; dan hutan sekunder meliputi hutan sekunder, hutan mangrove sekunder, dan hutan rawa sekunder. Hutan tanaman industri tidak termasuk dalam analisis karena tipe hutan ini memiliki pola manajemen tersendiri terkait dengan pengelolaan dan pemanfaatan tanaman kayu yang ada.

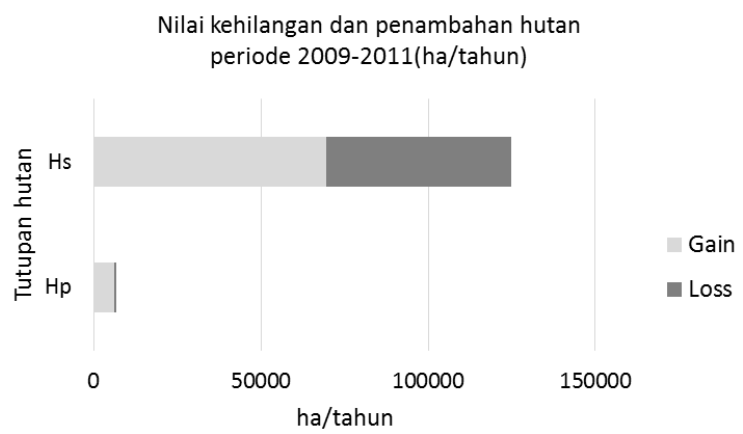

Gambar 3 Luas Kehilangan dan Penambahan Tutupan Hutan (ha/tahun) periode 2009-2011 (Sumber: Hasil Analisis, 2019)

Gambar 3 menunjukkan bahwa perubahan tutupan hutan sekunder sangat dinamis dengan nilai gain dan loss yang tinggi. Nilai kehilangan yang cukup tinggi pada hutan sekunder dibandingkan dengan hutan primer dapat menjadi informasi dasar bagi pengambil kebijakan untuk dapat melindungi hutan sekunder dengan lebih baik di masa yang akan datang sehingga dapat menekan nilai kehilangan di masa yang akan datang.

\subsection{Analisis Emisi Karbon}

Dari hasil perhitungan perubahan cadangan karbon sebagai akibat perubahan penutup lahan, maka dapat dilakukan estimasi perhitungan nilai emisi maupun serapan karbon. Gambar 4 menunjukkan perbandingan nilai emisi dan serapan karbon dimana total nilai emisi mencapai 20,2 $\mathrm{Mt} \mathrm{CO}_{2}$-eq/tahun, sedangkan total nilai serapan mencapai 15,4 $\mathrm{Mt} \mathrm{CO}_{2}$-eq/tahun. Dengan demikian, nilai emisi bersih mencapai sekitar 4,8 $\mathrm{Mt} \mathrm{CO}_{2}$-eq/tahun. Emisi terbesar sekitar $12 \mathrm{Mt} \mathrm{CO}_{2}$-eq/tahun disebabkan oleh deforestasi dimana terjadi perubahan hutan lahan kering sekunder menjadi lahan non hutan. Perubahan hutan lahan kering sekunder sebagian besar menjadi tanah terbuka dengan kontribusi emisi sekitar 8 Mt $\mathrm{CO}_{2}$-eq/tahun. Selanjutnya perubahan perkebunan menjadi permukiman juga berkontribusi emisi dengan nilai yang cukup besar sekitar 4,5 $\mathrm{Mt} \mathrm{CO}_{2}$-eq/tahun.

Sebaliknya, penyerapan karbon banyak terjadi sebagai akibat perubahan dari rawa menjadi pertanian lahan kering sebesar 9,5 Mt $\mathrm{CO}_{2}$-eq/tahun. Begitu juga dengan perubahan semak/belukar menjadi hutan rawa sekunder telah berkontribusi terhadap penyerapan karbon sebesar 9,5 $\mathrm{Mt} \mathrm{CO}_{2}$-eq/tahun. Nilai serapan yang cukup tinggi sebesar $9,2 \mathrm{Mt} \mathrm{CO}_{2}-$ eq/tahun juga terjadi sebagai akibat perubahan dari sawah menjadi tanah terbuka. 


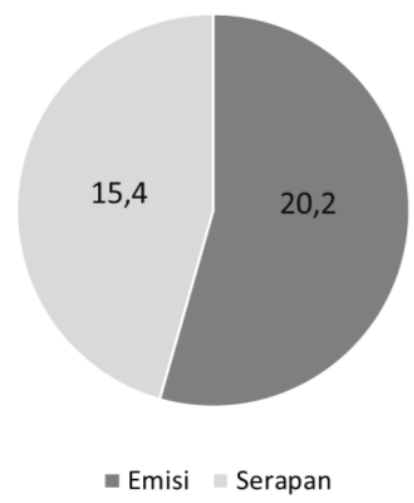

Gambar 4. Perbandingan Nilai Emisi dan Serapan Karbon (Mt CO2-eq/tahun) (Sumber: Hasil Analisis, 2019)
Berdasarkan hasil pemetaan sebaran emisi dan serapan karbon (Gambar 5), emisi karbon pada periode 2009-2011 meliputi area seluas 363.954,4 Ha, sedangkan serapan karbon meliputi area seluas 311.579,1 Ha. Peta persebaran ini dapat digunakan sebagai dasar kebijakan dalam pengelolaan lahan untuk dapat meningkatkan serapan karbon dan mengendalikan emisi karbon. Sebagai contoh pada zona emisi karbon (merah muda) perlu dilakukan konservasi atau peningkatan cadangan karbon melalui pemilihan tutupan lahan yang memiliki cadangan karbon tinggi. Informasi ini dapat pula menjadi dasar penataan ruang yang berbasis pengendalian emisi karbon.

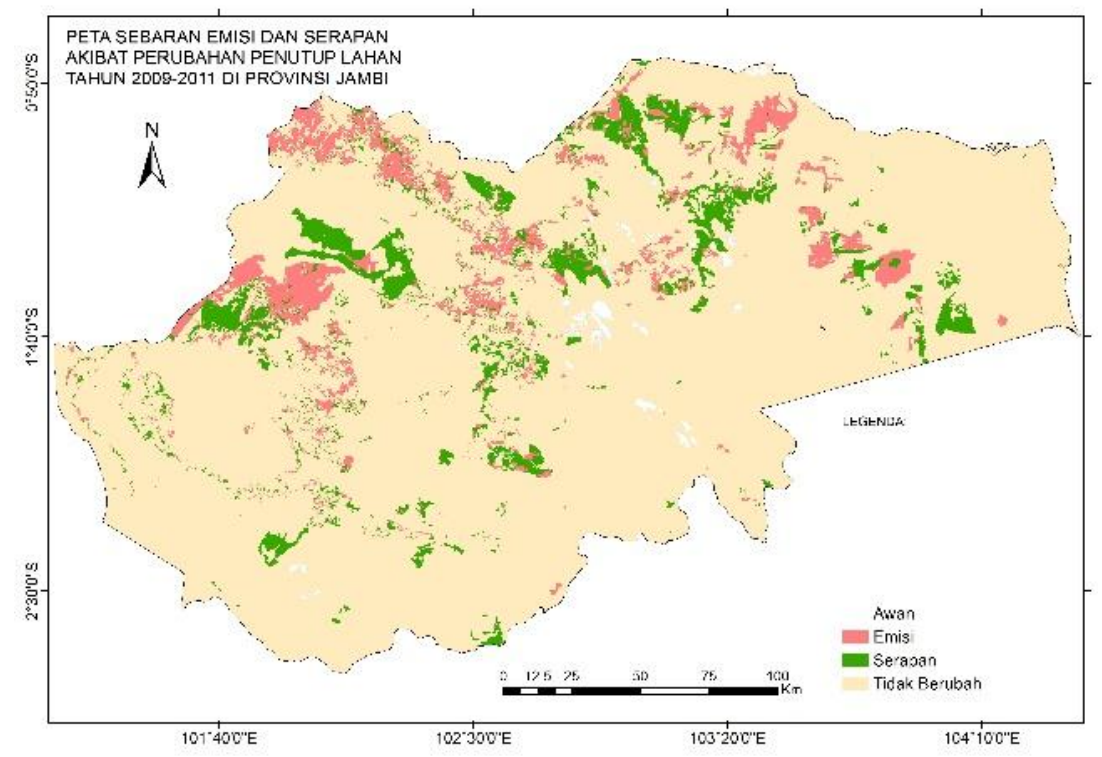

Gambar 5. Peta Sebaran Emisi dan Serapan Karbon Akibat Perubahan Penutup Lahan Tahun 2009-2011 (Sumber: Hasil Analisis, 2019)

\section{KESIMPULAN}

Dari hasil analisis perubahan penutup lahan dapat disimpulkan bahwa daya tarik terhadap tanaman yang memiliki nilai ekonomi yang tinggi telah mengakibatkan perubahan penutup lahan dimana meningkatnya luas area pertanian lahan kering bercampur dengan semak. Di antara penutup lahan hutan, hutan sekunder menunjukkan nilai kehilangan (loss) yang cukup tinggi. Untuk pengendalian penurunan hutan sekunder yang lebih dramatis diperlukan regulasi yang dapat mengendalikan perubahan hutan sekunder. Hutan sekunder memiliki peranan yang cukup penting dalam penyerapan karbon karena nilai cadangan karbon yang tinggi dan juga memiliki keanekaragaman hayati yang cukup tinggi pula.

Berdasarkan estimasi nilai emisi dan serapan karbon, nilai emisi di Provinsi Jambi pada periode 2009-2011 lebih tinggi dibandingkan dengan nilai serapan. Nilai emisi bersih ini mencapai sekitar $4.8 \mathrm{Mt} \mathrm{CO}_{2}$ eq/tahun, dimana penyumbang emisi tertinggi disebabkan oleh perubahan hutan sekunder menjadi non hutan. Hal ini mengindikasikan bahwa deforestasi yang terjadi pada periode 2009-2011 telah berkontribusi besar terhadap peningkatan emisi. Dari hasil analisis, emisi karbon banyak terjadi di daerah bagian utara Provinsi Jambi. Dengan demikina, informasi ini dapat digunakan sebagai dasar bagi para pengambil keputusan untuk dapat meningkatkan nilai serapan karbon misalnya 
dengan penataan ruang berbasis rendah emisi karbon.

\section{DAFTAR PUSTAKA}

BSN. 2010. Klasifikasi penutup lahan. Badan Standardisasi Nasional. Jakarta. 32 hal.

Ghazoul, J., \& D. Sheil. 2010. Tropical Rain Forest Ecology, Diversity, and Conservation. Oxford University Press Oxford.

IPCC. 2007. Climate Change: The Scientific Basis. Cambridge University Press: Cambridge.

$\mathrm{KLH}, 2010$. Indonesia Second National Communication Under The United Nations Framework Convention on Climate Change (UNFCCC). Kementerian Lingkungan Hidup. Jakarta. 200 hal.

$\mathrm{KLH}$. 2012. Pedoman Penyelenggaraan Inventarisasi Gas Rumah Kaca Nasional: Buku II. Pedoman Umum, Volume 3, Metodologi Penghitungan Tingkat Emisi dan Penyerapan Gas Rumah Kaca, Pertanian, Kehutanan dan Penggunaan Lahan Lainnya. Kementerian Lingkungan Hidup. Jakarta. 163 hal.

KLHK. 2014. Statistik Kementerian Kehutanan Tahun 2013. Jakarta. 320 hal.

KLKH. 2019. WebGIS Kementerian Lingkungan Hidup dan Kehutanan. Jakarta.

[terhubung berkala]. http://webgis.menlhk.go.id:8080/kemenhut/ index.php/id/fitur/unduhan [21 Mei 2019].

Malhi, Y., \& T. R. Marthews. 2013. Tropical forests: carbon, climate and biodiversity. In R. Lyster, C. MacKenzie, \& C. McDermott (Eds.), Law, Tropical Forests and Carbon: The Case of REDD+ (pp. 26-43). Cambridge University Press.

Marcus, B. A. 2009. Tropical Forests. Jones and Bartlett Publishers.

Rosa, I. M. D., M. J. Smith, O. R. Wearn, D. Purves, \& R. M. Ewers. 2016. The Environmental Legacy of Modern Tropical Deforestation. Current Biology, 26(16), 2161-2166. https://doi.org/10.1016/j.cub.2016.06.013

Stolle, F., K. M. Chomitz, E. F. Lambin, \& T. P. Tomich. 2003. Land use and vegetation fires in Jambi Province, Sumatra, Indonesia. Forest Ecology and Management, 179(1-3), 277-292. [terhubung berkala] https://doi.org/10.1016/S03781127(02)00547-9.

Tosiani, A. 2015. Buku Kegiatan Serapan dan Emisi Karbon. Kementerian Lingkungan Hidup dan Kehutanan, Direktorat Jenderal Planologi Kehutanan dan Tata
Lingkungan, Direktorat Inventarisasi dan Pemantauan Sumberdaya Hutan. Jakarta. 55 hal.

Wyman, M. S., \& T. V. Stein. 2010. Modeling social and land-use/land-cover change data to assess drivers of smallholder deforestation in Belize. Applied Geography, 30(3), 329-342. https://doi.org/10.1016/j.apgeog.2009.10.0 0 